\title{
DEGRADATION OF SULFAMETHAZINE BY SE-FENTON METHOD
}

\author{
DING, S. M. ${ }^{1,2^{*}}-\mathrm{LI}, \mathrm{M} .{ }^{1}$ \\ ${ }^{1}$ College of Chemistry and Chemical Engineering, Southwest University, Chongqing 400715, \\ China \\ ${ }^{2}$ Chongqing Multiple-Source Technology Engineering Research Center for Ecological \\ Environment Monitoring, Yangtze Normal University, Chongqing 408100, China \\ *Corresponding author \\ e-mail: ding717@126.com; phone: +86-133-8329-3867 \\ (Received $18^{\text {th }}$ Mar 2019; accepted $17^{\text {th }}$ May 2019)
}

\begin{abstract}
Photodegradation is one of the important methods of antibiotic treatment in water environment. This paper studies the treatment effect of sulfamethazine by solar electric-Fenton (SE-Fenton) technology, observes the contribution of $\mathrm{OH}$ concentration to degradation, and involves the effect of $\mathrm{pH}$ value, voltage and $\mathrm{Fe}^{2+}$ concentration on the treatment effect. The experiment shows that the degradation rate of sulfamethazine can be effectively improved by the solar-powered Fenton system. The optimum conditions for the degradation system are $\mathrm{pH} 3.0,25 \mathrm{mg} / \mathrm{L} \mathrm{Fe}^{2+}$ concentration, and the applied voltage of $3 \mathrm{~V}$. This study provides a basis for the removal of sulfonamide antibiotic contamination in water environment.
\end{abstract}

Keywords: sulfanilamide, solar electric-Fenton, antibiotics, photolysis, advanced oxidation technology

\section{Introduction}

The sulfonamide antibiotics are synthetic broad-spectrum antibiotics, with the structure of aminobenzene sulfonamide, and have been used in clinical medicine for 50 years. Because of its stable nature, convenient use and high safety, it is widely used in medicine. On the other hand, the absorption capacity of human beings or organisms is weak, and more than $80 \%$ of it is released into the environment in the original form, so it is often detected in the environment, with the detection rate ranking top among all kinds of drugs (Kolpin et al., 2002; Kemper, 2008). Because of its long-standing existence in the environment such as water and soil, it affects the original microbial population in the environment, gives birth to bacteria with extensive drug resistance, or induces gene mutations, thyroid hyperplasia or tumors in rodents (Martinez et al., 2008; Littlefieldna et al., 1989).

Due to the above reasons, the treatment technology of antibiotic pollution in the environment is getting more and more attention. Advanced oxidation technology is a water treatment technology developed in recent years, characterized by the generation of hydroxyl radicals $(\mathrm{OH})$ with strong oxidizing ability, and is a method of oxidizing macromolecule refractory organics into low toxic or non-toxic small molecule substance under the reaction conditions of high temperature and high pressure, electricity, sound, light, catalyst and the like (Oller et al., 2011). Fenton technology is often used for the treatment of refractory organics. With good treatment efficiency of Fenton method and high mineralization rate of organic pollutants, it is simple and practical, and its application range is increasing continuously. In recent years, solarFenton (S-Fenton), electric-Fenton (E-Fenton), ultrasonic-Fenton and other advanced 
oxidation technologies have been derived (Serna-Galvis et al., 2016). The Fenton technology forms hydroxyl radicals mainly by reaction, with the main reaction steps as follows (Christopher et al., 2007).

$$
\begin{gathered}
\mathrm{Fe}^{2+}+\mathrm{H}_{2} \mathrm{O}_{2} \rightarrow \mathrm{Fe}^{3+}+\mathrm{OH}^{-}+\mathrm{HO} \\
\mathrm{Fe}^{3+}+\mathrm{H}_{2} \mathrm{O}_{2} \rightarrow \mathrm{H}^{+}+\mathrm{Fe}\left(\mathrm{HO}_{2}\right)^{2+} \\
\mathrm{Fe}\left(\mathrm{HO}_{2}\right)^{2+} \rightarrow \mathrm{Fe}^{2+}+\mathrm{HO}_{2} \cdot \\
\mathrm{FeOH}{ }^{2+}+\mathrm{H}_{2} \mathrm{O}_{2} \rightarrow \mathrm{Fe}(\mathrm{OH})\left(\mathrm{HO}_{2}\right)^{+}+\mathrm{H}^{+} \\
\mathrm{Fe}(\mathrm{OH})\left(\mathrm{HO}_{2}\right)^{+} \rightarrow \mathrm{Fe}^{2+}+\mathrm{HO}_{2} \cdot+\mathrm{OH}^{-} \\
\mathrm{OH}+\text { Organics } \rightarrow \mathrm{H}_{2} \mathrm{O}+\text { Degradation products } \rightarrow \mathrm{CO}^{2+} \mathrm{H}_{2} \mathrm{O}
\end{gathered}
$$

On the basis of Fenton method and the application of light, the content of $\mathrm{Fe}^{2+}$ in Fenton reagent can be reduced, the reaction rate of $\mathrm{H}_{2} \mathrm{O}_{2}$ and the production rate of $\mathrm{OH}$ can be increased, so that the mineralization of organicsr can be more thorough (Elmolla and Chaudhuri, 2009, 2011). The E-Fenton method produces $\mathrm{Fe}^{2+}$ and $\mathrm{H}_{2} \mathrm{O}_{2}$ by electrochemical process. The E-Fenton method mainly involves the cathode E-Fenton method, the basic principle of which is to spray oxygen on the cathode of the electrolytic cell and reduce it to $\mathrm{H}_{2} \mathrm{O}_{2}$ at the cathode as shown in Equation 7. Then, $\mathrm{H}_{2} \mathrm{O}_{2}$ reacts with the added $\mathrm{Fe}^{2+}$ to produce $\cdot \mathrm{OH}$ and thus reacts with the organics (Brillas et al., 2009; Yahya et al., 2016).

$$
\mathrm{O}_{2}+2 \mathrm{H}^{+}+2 \mathrm{e}^{-} \rightarrow \mathrm{H}_{2} \mathrm{O}_{2}
$$

Compared with the S-Fenton method, the E-Fenton method has the mechanism of generating $\mathrm{H}_{2} \mathrm{O}_{2}$ automatically, and higher utilization rate of $\mathrm{H}_{2} \mathrm{O}_{2}$. The disadvantage is low current efficiency. If the amount of processing is very large, the amount of electricity input is increased and the cost will also be high, which limit its wide application. The photoelectric Fenton method, which combines the advantages of SFenton and E-Fenton, has attracted much attention in recent years. Compared with artificial light source, the low cost of sunlight makes it the research hotspot of S-Fenton method. The SE-Fenton technology simultaneously utilizes the characteristics of automatically generating $\mathrm{H}_{2} \mathrm{O}_{2}$ by the E-Fenton method and the advantage of circulating $\mathrm{Fe}^{2+} / \mathrm{Fe}^{3+}$ by $\mathrm{S}$-Fenton to increase the concentration of $\mathrm{OH}$, and save costs with sunlight. At present, the research is mainly applied to the treatment of refractory organics such as dyes and antibiotics (Valero et al., 2010; Mahmoodi et al., 2011; Almeida et al., 2015; Pérez et al., 2015, 2017). Casado and Fornaguera (2006) uses this method to treat organic acids such as p-benzoic acid, 2,4-dichlorophenoxyacetic acid and oxalic acid, and completely mineralize the organic acids for about $1 \mathrm{~h}$. Flox et al. (2007) also studied the degradation of phenol-containing wastewater and 4-chloro-ophenoxypropionic acid by SE-Fenton technology, with good results.

Sulfamethazine (SMT) is a kind of sulfonamides, which is mainly used to treat avian cholera, avian typhoid and chicken coccidiosis. More attempts have been made to treat sulfonamides with advanced oxidation technology (Alam et al., 2009; Batista and 
Nogueira, 2012; Sopaj et al., 2016). Because of its stability in the environment, the degradation effect needs to be further improved. In this paper, the SE-Fenton technology is used to treat SMT, which provides basic data for the treatment of antibiotic wastewater.

\section{Materials and methods}

\section{Drugs}

Sulfamethazine (SMT, purity is equal to or more than 99\%, SINOPHARM), methanol (chromatographic purity, Chengdu Kelong Chemical Reagent Factory), and acetonitrile (chromatographic purity, Tianjin Damao Chemical Reagent Factory). Ferrous sulfate (analytical purity), potassium dihydrogen phosphate (analytical purity), dipotassium hydrogen phosphate (analytical purity), sodium hydroxide and sulfuric acid are analytical purities. The experimental water is ultrapure water.

\section{Main instruments}

High Performance Liquid Chromatography (LC-2010A HT, Shimadzu, Japan); Circulating Water Vacuum Pump (Gongyi Yuhua Instrument Co., Ltd.), pH Meter (Shanghai LIDA Instrument Factory), TASI-8731 Digital Illuminometer (Suzhou TASI Electronics Co., Ltd.)

\section{Experimental device}

Experimental device of SE-Fenton is as Figure 1.

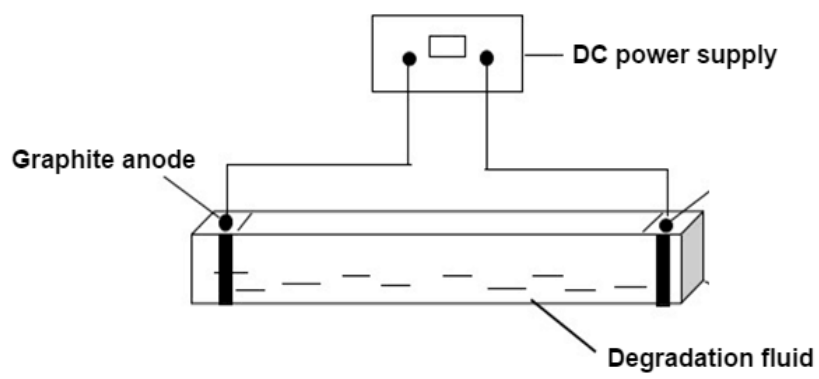

Figure 1. Experimental device

\section{Experimental method}

\section{Determination of SMT}

SMT in water is determined by HPLC with SHIMADZU VP-ODS-C18 column $(25 \mathrm{~cm} \times 4.6 \mathrm{~mm}, 5 \mu \mathrm{m})$. The detection wavelength is $270 \mathrm{~nm}$. Mobile phase: $0.017 \mathrm{~mol} / \mathrm{L}$ phosphate: Acetonitrile (80: 20) buffer solution; flow rate is $1 \mathrm{~mL} / \mathrm{min}$, sample volume is $20 \mu \mathrm{L}$, column temperature is $30^{\circ} \mathrm{C}$.

\section{Control experiment}

In the electrolyzing cell, $1 \mathrm{~L}$ of $10 \mathrm{mg} / \mathrm{L} \mathrm{SMT}$ standard working fluid is added, and $1 \mathrm{~mL}$ of $25 \mathrm{mg} / \mathrm{mL}$ ammonium ferrous sulfate solution is added. The $\mathrm{pH}$ of $\mathrm{NaOH}$ 
solution and $\mathrm{H}_{2} \mathrm{SO}_{4}$ solution is adjusted to be 3.0. Under different conditions, S-Fenton degradation, E-Fenton degradation (applied voltage $3 \mathrm{~V}$ ) and SE-Fenton degradation reaction were carried out. Take $1 \mathrm{~mL}$ of the reaction solution in the sampling bottle at different time intervals to determine the SMT concentration.

\section{Degradation of SMT under solar photovoltaic conditions}

In the electrolyzing cell, $1 \mathrm{~L} 10 \mathrm{mg} / \mathrm{L} \mathrm{SMT} \mathrm{standard} \mathrm{working} \mathrm{fluid} \mathrm{is} \mathrm{added,}$ $25 \mathrm{mg} / \mathrm{mL}$ ammonium ferrous sulfate solution is added. The $\mathrm{pH}$ of the solution is adjusted with $\mathrm{NaOH}$ solution and $\mathrm{H}_{2} \mathrm{SO}_{4}$ solution. Graphite electrodes are inserted on both sides of the electrolyzing cell, DC power supply is connected and applied voltage is regulated. The oxygen for manufacturing $\mathrm{H}_{2} \mathrm{O}_{2}$ is supplied to the degradation system with an aerator at the cathode.

For sunshine conditions, select the sunny days from July to August in Chongqing, from 11: 00 a.m. noon to 14: 00 p.m. The light intensity (600 00 780 00 LUX) empowers the degradation system to the degradation reaction under sunlight, and samples are taken at different time periods. The SMT concentration of the system is measured by high performance liquid chromatograph at different sampling time.

\section{Determination of $\cdot \mathrm{OH}$ in the process of degradation}

Because benzene reacts with $\cdot \mathrm{OH}$ to form phenol with good selectivity and few byproducts, benzene is often used as $\cdot \mathrm{OH}$ trapping agent to produce phenol, and its concentration represents the concentration of $\mathrm{OH}$ in solution. In preparing the degradation solution, add benzene, make the concentration of benzene in the degradation solution be $7000 \mu \mathrm{mol} \cdot \mathrm{L}^{-1}$, adjust to the desired $\mathrm{pH}$ value, carry out the degradation reaction, sample $1 \mathrm{~mL}$ at different time intervals as required, and determine phenol concentration in solution by high performance liquid chromatography. The determination conditions are as follows: SHIMADZU VP-ODS-C18 column $(25 \mathrm{~cm} \times$ $4.6 \mathrm{~mm}, 5 \mu \mathrm{m}$ ), column temperature of $30^{\circ} \mathrm{C}$, UV detector wavelength of $270 \mathrm{~nm}$, the mobile phase of methanol $(\mathrm{V})$ : Water $(\mathrm{V})=60: 40$, the flow rate of $1.0 \mathrm{~mL} \cdot \mathrm{min}^{-1}$, the injection volume of $20 \mu \mathrm{L}$, and the retention time of phenol as $3.01 \mathrm{~min}$.

\section{Results and discussion}

\section{Degradation of SMT by different Fenton systems}

Add $1 \mathrm{~mL}$ of $25 \mathrm{mg} / \mathrm{mL}$ ammonium ferrous sulfate solution to $1 \mathrm{~L}$ of $10 \mathrm{mg} / \mathrm{L}$ of SMT degradation solution, adjust the $\mathrm{pH}$ of the solution to be 3.0, and use E-Fenton, SFenton and SE-Fenton systems to degrade SMT, respectively. The degradation rate of SMT by different systems is shown in Figure $2 a$. From the figure, it can be seen that the degradation rate of three different Fenton systems increases with the increase of the reaction time. The $\mathrm{OH}$ produced during the degradation of three different systems is determined and the results are shown in Figure $2 b$. It is obvious that the degradation rate of SMT in different systems is positively related to the concentration of $\cdot \mathrm{OH}$ produced in the system. At the same time, the degradation rate of SMT is the highest by the SE-Fenton system, followed by the S-Fenton system and the lowest by the E-Fenton system. These results indicate that all three systems can promote the degradation of SMT, in which S-Fenton and E-Fenton technology can produce synergetic effect and enhance the degradation ability. However, the degradation effect of S-Fenton is better 
than that of E-Fenton, mainly because of the synergistic effect of ultraviolet light and $\mathrm{Fe}^{2+}$ on the catalytic decomposition of $\mathrm{H}_{2} \mathrm{O}_{2}$ produced in the system.
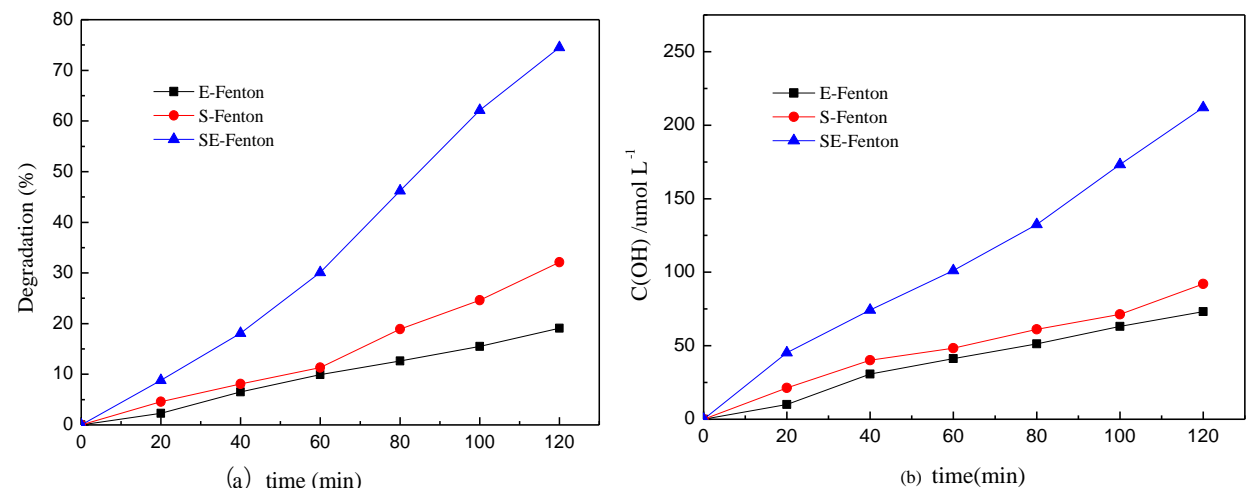

Figure 2. Degradation effect of SMT by different Fenton systems and the corresponding $O H$ concentration of the system. SMT $10 \mathrm{mg} / \mathrm{L}, \mathrm{pH}=3.0$, sunlight intensity (65000 78000 LUX)

\section{Effect of pH on SE-Fenton degradation of SMT}

Many studies have shown that Fenton systems usually have better ability to degrade organics under acidic conditions (Alam et al., 2009), so this experiment is carried out at $\mathrm{pH}$ 1.0, 3.0, 5.0, and 7.0. It can be seen from Figure 3 that in the reaction time of the first $30 \mathrm{~min}$, the degradation efficiency of SMT does not differ greatly under the conditions of $\mathrm{pH} 1.0,3.0$ and 5.0, and after $30 \mathrm{~min}$, the system with $\mathrm{pH} 3.0$ has the best effect on SMT degradation. When $\mathrm{pH}$ is higher than 3.0, ranging from 3.0 to 7.0 , the degradation efficiency of SMT becomes smaller and smaller. In the system with $\mathrm{pH} 7$, the degradation rate of SMT in $120 \mathrm{~min}$ is only about $10 \%$. When the $\mathrm{pH}$ is lower than 3.0, the degradation rate of SMT is also greatly reduced. Some studies have shown that when $\mathrm{pH}$ is less than 3.0, the ferric ion concentration in the Fenton system decreases, thus inhibiting the formation of $\mathrm{OH}$. When $\mathrm{pH}$ is higher than $4.0, \mathrm{Fe}(\mathrm{OH})_{3}$ precipitates will occur in the solution. The higher the $\mathrm{pH}$ is, the more precipitates will be formed, which will prevent the circulation of $\mathrm{Fe}^{2+}$ and $\mathrm{Fe}^{3+}$ in Fenton system and is unfavorable to the formation of $\mathrm{OH}$. Therefore, the optimum $\mathrm{pH}$ for SE-Fenton degradation of SMT is 3.0, and the $\mathrm{pH}$ of the system is 3.0 in the following experiments.

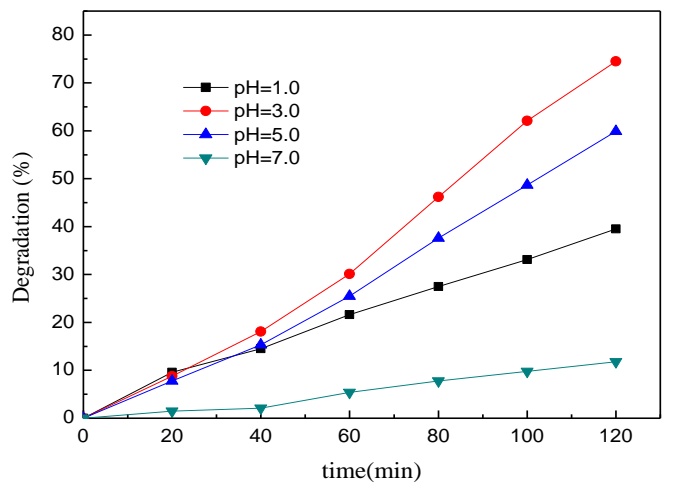

Figure 3. Effect of pH on SE-Fenton degradation of SMT. $1 \mathrm{~L} 10 \mathrm{mg} / \mathrm{L}$ SMT degradation solution; $E=3 \mathrm{~V} ; \mathrm{Fe}^{2+}$ concentration of $25 \mathrm{mg} / \mathrm{L}$; light intensity: $\mathrm{pH}=1.0(65500 \sim 72000 \mathrm{LUX})$; $p H=3.0(68000 \sim 72000$ LUX); $p H=5.0(64000 \sim 73500$ LUX); $p H=7.0(61300 \sim 72300$ LUX) 


\section{Effect of applied voltage on SE-Fenton degradation of SMT}

The degradation efficiency of the SMT increases as the applied voltage increases, as shown in Figure 4. This is due to an increase in the applied voltage of the electrolytic cell, which accelerates the generation of the cathode $\mathrm{H}_{2} \mathrm{O}_{2}$, resulting in an increase in the concentration of $\cdot \mathrm{OH}$. The difference among the voltages $3 \mathrm{~V}, 5 \mathrm{~V}$ and $7 \mathrm{~V}$ used in the experiments is not too large, so the degradation efficiency of SMT is not improved significantly. The influence of the applied voltage of $3 \mathrm{~V}$ and $7 \mathrm{~V}$ on SMT degradation is very small. In view of saving cost and energy, under this experimental condition, when the applied voltage is $3 \mathrm{~V}$, the degradation effect of SMT is the best.

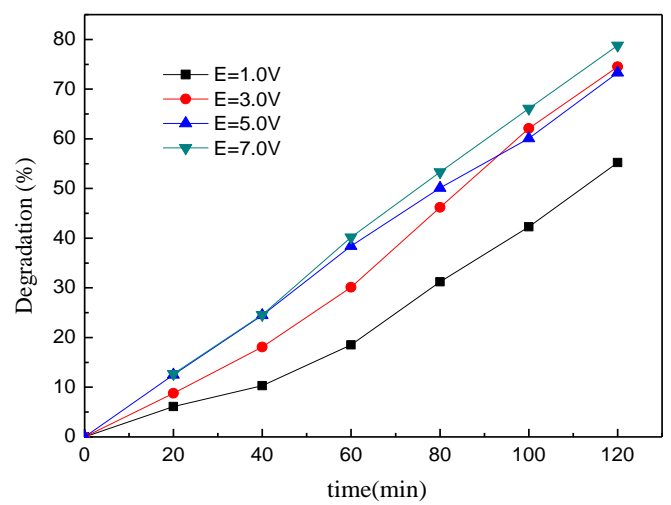

Figure 4. Effect of applied voltage on SE-Fenton degradation of SMT. $1 \mathrm{~L} 10 \mathrm{mg} / \mathrm{L} S M T$ degradation solution; $\mathrm{pH}=3 ; \mathrm{Fe}^{2+}$ concentration of $25 \mathrm{mg} / \mathrm{L}$; Light intensity: $\mathrm{E}=1.0 \mathrm{~V}$ (65000 76000 LUX); $E=3.0 \mathrm{~V}(65000 \sim 78000$ LUX); $E=5.0 \mathrm{~V}(55000 \sim 70000$ LUX); $E=7.0$ $V(56700 \sim 69700$ LUX)

\section{Effect of $\mathrm{Fe}^{2+}$ dosage}

The results of Figure 5 show that in the range of concentration given in the experiment, when the concentration of $\mathrm{Fe}^{2+}$ is $25 \mathrm{mg} / \mathrm{L}$, the degradation effect of SMT is the best.

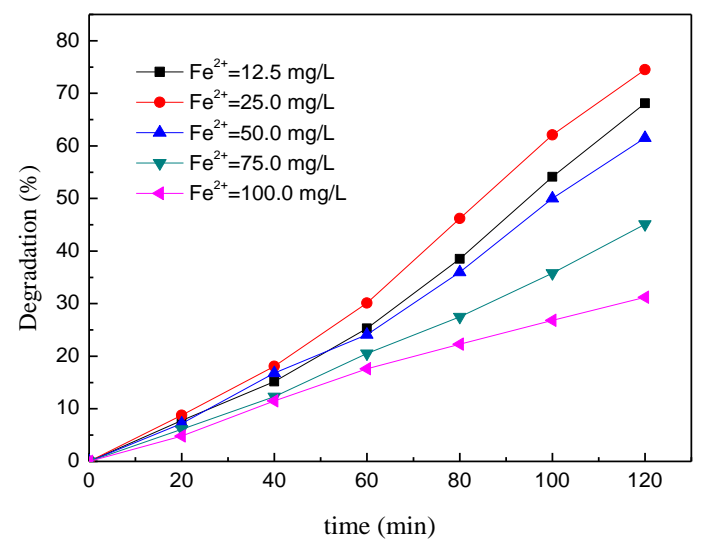

Figure 5. Effect of $\mathrm{Fe}^{2+}$ dosage. $\mathrm{E}=3 \mathrm{~V} ; \mathrm{pH}=3 ; 10 \mathrm{mg} / \mathrm{L}$ SMT Degradation solution; Light intensity: $\mathrm{Fe}^{2+}=12.5 \mathrm{mg} / \mathrm{L}(64000-70000 \mathrm{LUX}) ; \mathrm{Fe}^{2+}=25 \mathrm{mg} / \mathrm{L}(65000-78000 \mathrm{LUX})$; $\mathrm{Fe}^{2+}=50 \mathrm{mg} / \mathrm{L}(63000 \sim 75000 \mathrm{LUX}) ; \mathrm{Fe}^{2+}=75 \mathrm{mg} / \mathrm{L}(63000 \sim 75700 \mathrm{LUX}) ; \mathrm{Fe}^{2+}=100 \mathrm{mg} / \mathrm{L}$ (64200 76000 LUX) 
When $\mathrm{Fe}^{2+}$ concentration is lower than this value, the degradation rate decreases. When the concentration of $\mathrm{Fe}^{2+}$ is higher than this value, the higher the concentration is, and the lower the degradation effect of SMT is. This is because a suitable concentration of $\mathrm{Fe}^{2+}$ will improve the utilization efficiency of $\mathrm{H}_{2} \mathrm{O}_{2}$, too low $\mathrm{Fe}^{2+}$ is not sufficient to decompose $\mathrm{H}_{2} \mathrm{O}_{2}$, and less $\cdot \mathrm{OH}$ produced is not conducive to degradation. Some studies have shown that excessively high concentration of $\mathrm{Fe}^{2+}$ will decompose $\mathrm{H}_{2} \mathrm{O}_{2}$, which is unfavorable to the formation of $\cdot \mathrm{OH}$, resulting in the decrease of the degradation effect of SMT (Sire's et al., 2007).

\section{Conclusions}

(1) Under the same conditions, the degradation rate of sulfamethazine is $32.1 \%$, $19.1 \%$ and $74.5 \%$ respectively by S-Fenton, E-Fenton and SE-Fenton systems separately. The degradation rate of sulfamethazine is greatly improved by SE-Fenton technology, and the advantages of the combined technologies are demonstrated by comparison with those of S-Fenton and E-Fenton.

(2) The results show that $\mathrm{OH}$ produced by SE-Fenton system is positively related to the degradation rate of SMT. Under the same conditions, the concentration of $\cdot \mathrm{OH}$ produced in the degradation process of S-Fenton, E-Fenton and SE-Fenton in $120 \mathrm{~min}$ is $92 \mu \mathrm{mol} \cdot \mathrm{L}^{-1}, 73.2 \mu \mathrm{mol} \cdot \mathrm{L}^{-1}$ and $212 \mu \mathrm{mol} \cdot \mathrm{L}^{-1}$ respectively, which indicates that the synergistic mechanism of photo-electric interaction in SE-Fenton system promotes the production of $\cdot \mathrm{OH}$.

(3) In this experimental system, the optimum conditions for degradation of $1 \mathrm{~L}$ $10 \mathrm{mg} / \mathrm{L}$ SMT by SE-Fenton technology are as follows: $\mathrm{pH}$ is 3.0, concentration of $\mathrm{Fe}^{2+}$ is $25 \mathrm{mg} / \mathrm{L}$, and the applied voltage is $\mathrm{E}=3 \mathrm{~V}$, which has the best degradation effect.

(4) Solar photoelectric Fenton technology has good degradation efficiency for sulfonamide, but because of the unstable sunlight and $\mathrm{pH}=3$ as the optimum degradation condition, the application of solar photoelectric Fenton technology is limited. Further research and development of sulfonamide degradation technology and methods in near-neutral water are needed.

Acknowledgements. This work was financially supported by Natural Science and Technology Project of Chongqing Municipal Education Commission (No. KJ111311).

\section{REFERENCES}

[1] Alam Trovo, G., Raquel Nogueira, F. P., Ana, A., Amadeo, R. (2009): Degradation of sulfamethoxazole in water by solar S-Fenton. Chemical and toxicological evaluation. Water Research 43: 3922-3931.

[2] Almeida, L. C., Silva, B. F., Zamomi, M. V. (2015): Photoelectrocatalytic/photo EFenton coupling system using a nanostructured photoanode for the oxidation of a textile dye: kinetics study and oxidation pathway. - Chemosphere 136: 63-71.

[3] Batista, A. P., Nogueira, R. P. (2012): Parameters affecting sulfonamide S-Fenton degradation - iron complexation and substituent group. - Journal of Photochemistry and Photobiology A: Chemistry 232: 8-13.

[4] Brillas, E., Sirés, I., Oturan, M. A. (2009): E-Fenton technology and related electrochemical technologies based on Fenton's reaction chemistry. - Chemical Reviews 109(12): 6570-631. 
[5] Casado, J., Fornaguera, J. (2006): Pilot scale mineralization of organic acids by E-Fenton process plus sunlight exposure. - Water Research 40: 2511-2516.

[6] Christopher, K., Duesterberg, T., David, W. (2007): Kinetic modeling of the oxidation of p-hydroxybenxoic acid by Fenton's reagent: implications of the role of quinones in the redox cycling of iron. - Environ. Sci. Technol 41: 4103-4110.

[7] Elmolla, E. S., Chaudhuri, M. (2009): Degradation of the antibiotics amoxicillin, ampicillin and cloxacillin in aqueous solution by the S-Fenton technology. - Journal of Hazardous Materials 172(2-3): 1476-1481.

[8] Elmolla, E. S., Chaudhuri, M. (2011): Combined S-Fenton-SBR process for antibiotic wastewater treatment. - Journal of Hazardous Materials 192(3): 1418-1426.

[9] Flox, C., Pere-Llus, C., Centellas, F. et al. (2007): Solar photo E-Fenton degradation of cresols using a flow reactor with a boron-doped diamond anode. - Applied Catalysis B: Environmental 75: 17-28.

[10] Kemper, N. (2008): Veterinary antibiotics in the aquatic and terrestrial environment. Ecol. Indic. 8: 1-13.

[11] Kolpin, D. W., Furlong, E. T., Meyer, M. T. E., Zaugg, S. D., Barber, L. B., Buxton, H. T. (2002): Pharmaceuticals, hormones, and other organic wastewater contaminants in U.S. streams, 1999-2000: A national reconnaissance. - Environmental Science and Technology 36(6): 1202-1211.

[12] Littlefieldna, N. A., Gaylor, D. W., Blackwell, B. N., Allen, R. R. (1989): Chronic toxicity/carcinogenicity studies of sulpha meth azine in B6C3F1 mice. - Food Chem Toxicol 27(7): 455-463.

[13] Mahmoodi, N. M., Salchi, R., Arami, M. (2011): Binary system dye removal from colored textile wastewater using activated carbon: kinetic and isotherm studies. Desalination 272(1/2/3): 187-195.

[14] Martinez, J. L., Baquero, F., Canton, R. (2008): Antibiotics and antibiotic resistance in water environments. - Current Opinion in Biotechnology 19(3): 260-265.

[15] Oller, I., Malato, S., Sanchez-Perez, J. A. (2011): Combination of advanced oxidation processes and biological treatments for wastewater decontamination - a review. - Science of the Total Environment 409(20): 4141-4166.

[16] Pérez, T., Garcia-Segura, S., El-Ghenymy, A. (2015): Solar photoE-Fenton degradation of the antibiotic metronidazole using a flow plant with a Pt/air-diffusion cell and a CPC photoreactor. - Electrochimica Acta 165(9): 173-181.

[17] Pérez, T., Sirés, I., Brillas, E., Nava, J. L. (2017): Solar photoE-Fenton flow plant modeling for the degradation of the antibiotic erythromycin in sulfate medium. Electrochimica Acta 228: 45-56.

[18] Serna-Galvis, E. A., Silva-Agredo, J., Giraldo, A. L., Florez, O. A., Torrespalma, R. A. (2016): Comparison of route, mechanism and extent of treatment for the degradation of a $\beta$-lactam antibiotic by $\mathrm{TiO} 2$, photocatalysis, sonochemistry, electrochemistry and the SFenton system. - Chemical Engineering Journal 284: 953-962.

[19] Sire's, I., Gamrrido, J. A., Mari'a, R. (2007): Catalytic behavior of the Fe3+/Fe2+ system in the E-Fenton degradation of the antimicrobial chlorophene. - Applied Catalysis B: Environmental 72: 382-394.

[20] Sopaj, F., Oturan, N., Pinson, J., Oturan, M. A. (2016): Effect of the anode materials on the efficiency of the E-Fenton technology for the mineralization of the antibiotic sulfamethazine. - Applied Catalysis B Environmental 199: 331-341.

[21] Valero, D., Ortiz, J. M., Expósito, E., Montiel, V., Aldaz, A. (2010): Electrochemical wastewater treatment directly powered by photovoltaic panels: electrooxidation of a dyecontaining wastewater. - Environmental Science \& Technology 44(13): 5182-5187.

[22] Yahya, M. S., El, K. M., Oturan, N., Ei Kacemi, K., Oturan, M. A. (2016): Mineralization of the antibiotic levofloxacin in aqueous medium by E-Fenton technology: Kinetics and intermediates products analysis. - Environmental Technology 37(10): 1276-1287. 